\title{
Study on the Changes of Urban Green Space with Remote Sensing Data: a Comparison of Nanjing and Greater Manchester
}

\author{
Haixia Zhao $^{1 *}$, Tianyuan Zhu ${ }^{1}$, Shufen Wang ${ }^{2}$, Sarah Lindley ${ }^{3}$ \\ 'Key Laboratory of Watershed Geographic Sciences, Nanjing Institute of Geography and Limnology, \\ Chinese Academy of Sciences, Nanjing 210008, China \\ ${ }_{2}^{2}$ Jiangsu Provincial Academy of Environmental Science, Nanjing 210008, China \\ ${ }^{3}$ School of Environment, Education and Development, The University of Manchester, \\ Manchester M13 9PL, United Kingdom
}

Received: 5 February 2021

Accepted: 25 May 2021

\begin{abstract}
Green space effectively maintains urban ecological environment, improves life quality, and promotes sustainable development. Taking Nanjing and Greater Manchester as study cases, based on the land use data from remote sensing interpretation, this study used a combination of mathematical statistics and GIS spatial analysis methods to analyze the evolution of green spatial patterns in terms of general characteristics, gradient characteristics and evolution characteristics, in order to provide scientific reference for the protection of green space and sustainable urban development in Nanjing. Results showed that the green space has increasingly decreased from 2000 to 2010 in Nanjing, and in Greater Manchester, decreased first, then increased from 2000 to 2011. The area of green space gradually increased from the central area to the suburbs and the suburbs in both cities, and in Nanjing it significantly changed in the suburbs and outer suburbs, while in Greater Manchester the changes were mainly in central and suburban areas. We also found that the new towns were the main transfer areas of cold spots while the central areas are mainly the hot spots transfer areas in Nanjing, and outspread shrinkage was the main evolution model; meanwhile, in Greater Manchester, green space had a lower changing intensity as well as smaller cold \& hot spots numbers and more scattered distribution, and the evolution model was dominated by endocytosis-type in construction land. This study argued that Nanjing should improve the compactness of the city and regulate the relationship between construction land and green space through land redevelopment and functional replacement within construction land.
\end{abstract}

Keywords: green space, evolution analysis, urban environment, Nanjing, Greater Manchester

*e-mail: 1047649348@qq.com 


\section{Introduction}

Urban green spaces are regional spaces composed of outdoor green area and other ecological lands such as waters and farmland [1-4]. They exist in cities mainly as semi-natural areas, managed parks and gardens, supplemented by scattered vegetated pockets associated with roads and incidental locations [5]. As one of the basic elements of a city [6], it plays a critical role in maintaining biodiversity and providing important ecosystem services in urban areas [7, 8], and the condition of green spaces underpins the functioning of urban ecosystems [9]. They also provide the primary contact with biodiversity and the natural environment for residents [10], and may influence their physical and mental well-being $[11,12]$.

With the rapid urbanization and growing urban populations, the demand for more land used for development can be intense [13], which makes green space concede to construction land. In some areas the intensity of land use has far exceeded the international warning line of $30 \%$, resulting in the continuous reduction of the scale of green space such as farmland and lakes, aggravating the degree of fragmentation and restricting the multiple functions of green space in ecological maintenance and protection. For example, a lack of co-ordination in green space provision, accompanied by rapid urban growth in Copenhagen during the 1990s, resulted in great pressure on the green space network [14]. On the other hand, residents' life demands have also changed from simple economic income to a more convenient and comfortable living environment, from dependence on economy and construction space to desire of leisure and green space [15], so the scarcity and importance of green space become increasingly prominent. Therefore, the construction of green space lagging behind the construction of cities has become the main restriction on sustainable development of cities [16].

A large number of studies have quantitatively investigated the spatiotemporal changes of green space and mainly focused on three aspects: scale changes, land-use transitions and landscape metrics. Green space scale changes and type shifts are usually based on land use/cover changes [17-20]. Satellite remote sensing has the advantages of macroscopic, dynamic, and continuous spatial coverage, which can obtain ground information intuitively and dynamically. It can effectively monitor the changes in land use/cover data [18], which is an absolute advantage [21]. It has gradually become an important tool for analyzing changes in green space. $\mathrm{Li}$ et al. used Landsat remote sensing image data to quantitatively study the changes in the green space inside the built-up area from the changes in multiple indicators [22]. Di et al. [23], Li et al., [24] deciphered the land use cover based on remote sensing images and analyzed its overall area change and the area change of different land use types by applying statistical methods to the data respectively. Other scholars used indicators such as intensity of change and dynamic attitude to describe the characteristics of green spatial scale change $[25,26]$, but such quantitative analysis was not available for the change of change rate in different areas of the city. The change in green space type is directly derived from the transformation between land use types, thus the transfer matrix model of ArcGIS platform has been widely used in previous studies. The transformation matrix can be used to obtain information on changes in the internal composition and structure of green space, and landscape indices have been widely used in the study of green space pattern changes [27-31], combined with Fragstats software for analyZis to reflect green space landscape characteristics and their changes. Multiple indices are generally selected from three levels: patch, type and landscape to characterise the patchiness, connectivity and fragmentation of green space. Among them, the landscape division (DIVISION), splitting index (SPLIT) and effective mesh index (MESH), are considered to be better indicators of the fragmentation process of green space than other traditional indices [32]. However, these studies always compared several metrics to analyze the landscape change without considering its complicated characteristics. Overall, the previous studies have quantified the green space dynamics from the perspective of scale, land-use transition, and landscape metrics, while few considered the specific spatial variation of change rate and the internal process of green area expanding or contracting. In this case, accurately estimating the pattern of green space change and its interaction with construction space will be difficult, which is not conducive to the planning and optimization of green space. Hence, more thorough analysis of green space dynamic characteristics and evolution mode under the continuous development of urban construction is urgently needed.

Nanjing, as an important traditional industrial base in China, is in the stage of rapid development, the urbanization process being fast and the built-up area expanding continuously, which makes the contradiction between economic development and green space construction still prominent, and ecological pressure is relatively large. In the new round of cities' development competition, Nanjing is largely restricted by the ecological environment. Greater Manchester is a city where urbanization began early. After reviving from the painful period of social and economic transformation, it has entered a stage of stable development, having transformed and upgraded the industry and paying close attention to urban environmental management and green space construction. It has achieved remarkable results in green space development and gradually realized the integrated development of economy and environment. Nanjing and Manchester are both first-tier cities in their country and perform similar functions in the city cluster. Taking Nanjing and Greater Manchester as study cases, we combined remote sensing, GIS technology and statistical methods to compare the changes of green space in two cities. The objectives of 
this study are as follows: (1) recognizing the distribution of green space in the two cities; (2) analyzing the changes of green space pattern in the two cities; (3) analyzing the dynamic evolution of green space in the two cities. This may also provide useful information for the coordinated development of economic construction and ecological protection in Nanjing.

\section{Study Area}

Nanjing is the capital of Jiangsu province of China and consists of 11 districts including Qinhuai, Jianye, Xuanwu, Gulou, Pukou, Qixia, Yuhuatai, Jiangning, Liuhe, and Lishui, covering a total area of $4388 \mathrm{~km}^{2}$. Since the Reform and Open Policy, the urbanization and economic in Nanjing have developed rapidly, with a huge population of $8.24 \times 10^{6}$ and a GDP of USD $1.45 \times 10^{11}$ in 2015. Pursuing for the quality urbanization and graceful living environment, Nanjing has implemented policies to develop and improve the green space, which made the greening rate in builtup areas increase from $44.38 \%$ to $44.47 \%$ during 2010 to 2015 , and the number of parks also increased from 62 to 127 . However, due to the excessive development and unrestrained construction of new town district, development zones and industrial park, in 2015, Nanjing's construction land area ran up to $1864 \mathrm{~km}^{2}$ and urban development intensity was $28.06 \%$ exceeding the value $21 \%$ in France and the 24\% in Greater London of the UK, which led to the substantial reduction of green space area such as basic farmland, water area or forest, and the overall structure, efficiency and ecological security were also affected negatively [33].

Located in the northwest of England, Greater Manchester spans an area of $1,276 \mathrm{~km}^{2}$ and was established in 1974. It is the third largest metropolitan area in the UK. After the Second World War, Greater Manchester has entered a post-industrial era and the industry has successfully transformed and upgraded, the degraded traditional industries gradually transforming into financial, education, tourism, and commercial services, and the service industry becoming a leading industry. In the process of urban revitalization, Greater Manchester attempted to restrict the urban expansion by creating urban green belts, and achieved remarkable results in green space construction, resulting in the extensive increase of green space in all major cities and the relatively balanced distribution. The proportion of green space is more than $65 \%$ in Rockdale and Oldham and over $50 \%$ in Wigan, Bolton and Bailey, which are at a high level in the UK and even Europe. Greater Manchester has more than 160 green parks so far, and the green space has developed fast, especially from 2007 to 2011, during which the green area increased from $54.84 \%$ to $55.08 \%$ and the per capita public green area rose to $30.8 \mathrm{~m}^{2}$, thus the residents' quality of living has shown an obvious improvement.

\section{Data and Methods}

\section{Data Sources and Processing}

In order to reflect the scale changes and evolution laws of green spaces in different periods directly and dynamically, this study used remote sensing image data to carry out research on the evolution of green spaces. The primary data used in this study was obtained from satellite images including Landsat TM images in 2000, 2005 and 2010 of Nanjing and Landsat TM images in 2000, 2007 and 2011 of the Greater Manchester, with spatial resolution of $30 \mathrm{~m} \times 30 \mathrm{~m}$. Firstly, use ENVI software for preprocessing, mainly including geometric correction, atmospheric correction and image cropping. In order to extract the land-use types of Nanjing and the Greater Manchester, the Yangtze River Delta land use maps of 1:100,000 in 1995 and 2005 and of 1:25,000 in 2000 and 2010, provided by National Earth System Science Data Sharing Infrastructure (http://www. geodata.cn), are used as a reference to interpret the satellite images of Nanjing, and the UK land use maps from website http://www.digimap.com is referenced in the interpretation of the Greater Manchester satellite images. According to the LUCC classification system of IGBP, based on the purposes in this research and actual situations of the study area, the land cover was reclassified to five different categories: farmland, forest land, grassland, water area and construction land. The farmland, woodland, grassland and water area were designated as green space by using maximum likelihood classification. The results were great, showing that the overall accuracy of classification is better than $85 \%$.

\section{Designation of Gradient}

Considering the current situation of land use, spatial development intensity, population density and urban layout planning, the whole study area is divided into three regions: Central area, suburb and outer suburb. In Nanjing, with a population density of over 10,000 persons $/ \mathrm{km}^{2}$, the area surrounded by The Nanjing Circumvallation is divided into the central area, including the most of the streets in Xuanwu, Gulou and Qinhuai; suburbs are areas where the population density is $1,000-10,000$ persons $/ \mathrm{km}^{2}$ in 2010 and that are $20 \mathrm{~km}$ away from the downtown, including all the streets in Jianye and some in Gulou, Yuhuatai, Jiangning, Pukou and Qixia; area that are 20-40km away from Xinjiekou and where the population density is less than 1,000 persons $/ \mathrm{km}^{2}$ are designated as outer suburb, according to the 'Nanjing city master plan (2007-2030), (Fig. 1a). In Greater Manchester, the downtown area where the construction land proportion is more than $95 \%$ is divided into central area; the region with a land use intensity of more than $80 \%$ and a distance of $9 \mathrm{~km}$ away from the center is defined as suburban area, including most of the area of Salford, Stockport, Tameside and Trafford; and areas where the population density is above 
1300 persons $/ \mathrm{km}^{2}$ as well as the distance to the central is $36 \mathrm{~km}$ are designated as the outer suburb (Fig. 1b).

According to the spatial division of the central area-the suburban area-the outer suburbs, the division combined the urban spatial layout with urban scale. For Nanjing, taking Xinjiekou as the center, divided it into several circles at distances of $5 \mathrm{~km}, 10 \mathrm{~km}, 15 \mathrm{~km}$, $20 \mathrm{~km}, 25 \mathrm{~km}, 30 \mathrm{~km}, 35 \mathrm{~km}, 40 \mathrm{~km}, 45 \mathrm{~km}, 50 \mathrm{~km}$ and $55 \mathrm{~km}$; and for Greater Manchester, taking Manchester as the center, divided the city into circles with radii of $3 \mathrm{~km}, 6 \mathrm{~km}, 9 \mathrm{~km}, 12 \mathrm{~km}, 15 \mathrm{~km}, 18 \mathrm{~km}, 21 \mathrm{~km}, 24 \mathrm{~km}$, $27 \mathrm{~km}, 30 \mathrm{~km}, 33 \mathrm{~km}$ and $36 \mathrm{~km}$. The gradient change of green space is examined in terms of the distribution and intensity.

\section{Evolution Patterns Analysis}

Getis - Ord Gi* is used to identify the space of high value and low value cluster, namely hot zone and cold zone, whose changing pattern will help analyze the evolution of regional green space [34]. The calculation formula is as follows:

$$
G_{i}^{*}(d)=\sum_{j}^{n} W_{i j}(d) X_{j} / \sum_{j}^{n} X_{j}
$$

In order to facilitate the interpretation and comparison, standardized method is used. The formula is as follows:

$$
\mathrm{Z}\left(G_{i}^{*}\right)=\frac{G_{i}^{*}-E\left(G_{i}^{*}\right)}{\sqrt{\operatorname{Var}\left(G_{i}^{*}\right)}}
$$

In the formula, $\mathrm{E}\left(\mathrm{Gi}^{*}\right)$ and $\operatorname{Var}\left(\mathrm{Gi}^{*}\right)$ are the mathematical expectation and variance for $\mathrm{Gi}^{*}$, and Wij(d) is the spatial weight. If $\mathrm{Z}\left(\mathrm{Gi}^{*}\right)$ is positive and significant, it indicates that the values around by the position I are relatively high (higher than the mean) and belong to the high value of spatial agglomeration (hot spots). On the other hand, if $\mathrm{Z}\left(\mathrm{Gi}^{*}\right)$ is negative and significant, it is shown that the values around the position I are relatively low (below the mean) and belong to the low spatial agglomeration (cold spots).

\section{Evolution Model Analysis}

The expansion of construction land causes the proportion change of green space directly, and will present different expansion models under the combined effects of various factors [35]. Generally, the models can be divided into filling type, spreading type (including looped expansion and axial expansion) and enclaving type. The construction space and the green space are mutually complementary, so that the expansion model of the construction land will inevitably affect the evolution model and process of green space. Based on the expansion models of construction land, the green space evolution model is summarized as four types: outspread shrinkage, corridor-cut shrinkage, endocytosed shrinkage and perforated shrinkage (Fig. 2). According to the newly overall planning of Nanjing, the areas with drastic changes in construction land such as the main city, sub-city of Jiangbei, Xianlin and Dongshan and Longtan were selected as research units; and the built-up area of Greater Manchester selected on ArcGIS platform serves as the other research unit. First, extract new construction areas in different periods, then use the minimum bounding box method [36] and the convex shell model method [37-39] synthetically to determine the expansion model of construction land. Secondly, with the Erase-tool on ArcGIS platform, extract the new and contracted green spaces of Nanjing and Greater Manchester research units in different periods. Finally, the extracted new or contracted green space is superimposed with the construction land evolution model in the same period to analyze the model of green space evolution in different periods.
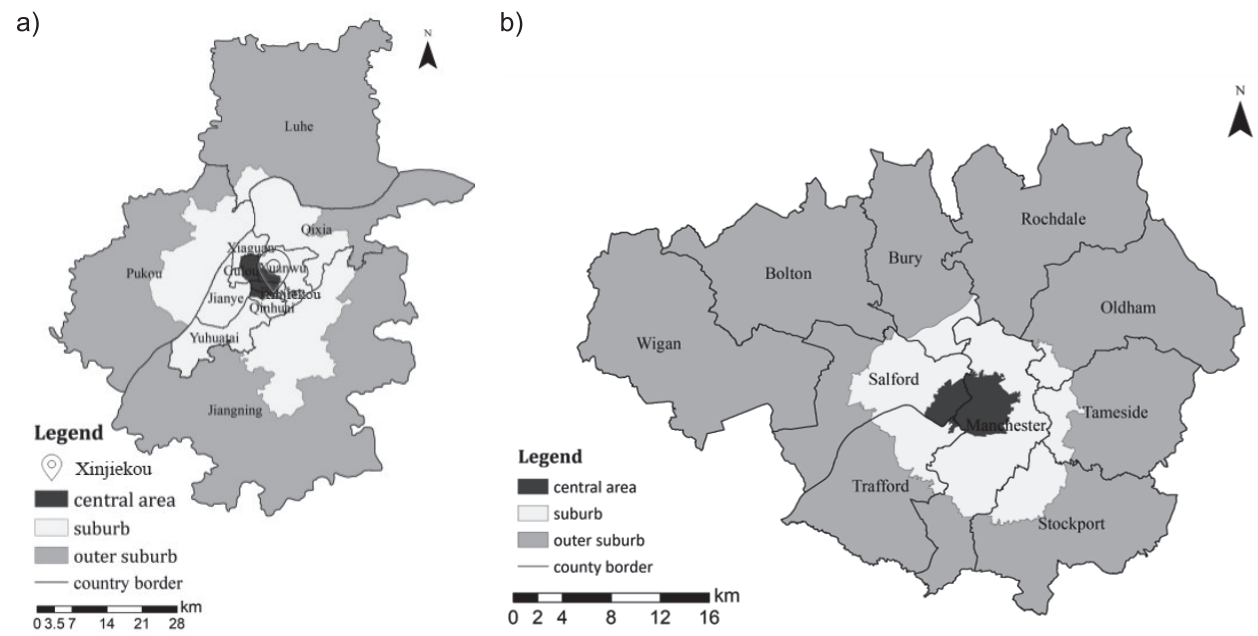

Fig. 1. Regional division in Nanjing and Greater Manchester a) Nanjing, b) Greater Manchester. 


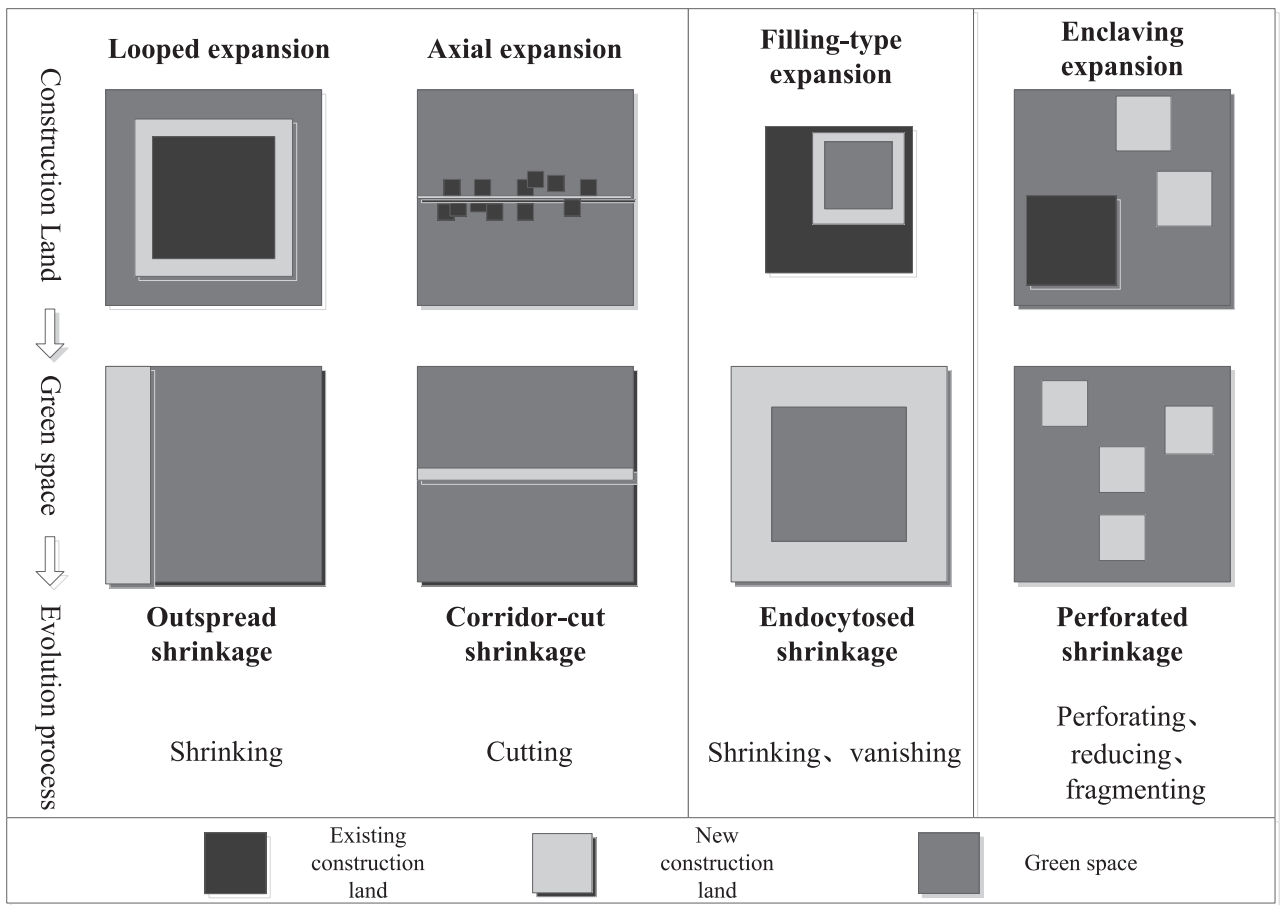

Fig. 2. Evolution model of green space.

\section{Results}

\section{Synoptic Characteristics}

Affected by urban construction expansion, the green spatial pattern in metropolitan area reveals a general trend of shrinkage. However, with the increasing demands of people for green space, green space construction has shown an expanding trend for the long term, but the extent of green space expansion is limited because of overall urban scale restrictions.

During 2000-2010, green space of metropolitan area in Nanjing revealed the shrinkage trend, but the pace of decline was getting slow. In 2000, the area of green space was $3671.37 \mathrm{~km}^{2}$ which accounting for $83.67 \%$ of the total area; and in 2005, the green space area was reduced by $328.41 \mathrm{~km}^{2}$, with an average shrinkage at annualized rate of $1.79 \%$. Afterwards, the green space area shrank further with an annual rate of $1.54 \%$, which has reduced to $3086.37 \mathrm{~km}^{2}$ by 2010 , accounting for $70.34 \%$ of the whole region and dropping by $13 \%$. The area of farmland greatly was decreased by $636.12 \mathrm{~km}^{2}$ during 2000-2010, which was the most reduction (Table 1). In recent years, Nanjing has strengthened efforts in city greening, lakes and water area dredging and wetland restoration along the Yangtze River, etc. and has produced a marked effect, but it's still not sufficient to offset a general trend of shrinkage in green space area caused by substantial reduction in farmland.

During 2000-2011, green space of Greater Manchester showed a trend of shrinkage at first and then expansion, but the change rate was far lower than Nanjing and was relatively steady. In 2000, green space area of Greater Manchester was $729.68 \mathrm{~km}^{2}$, accounting for $57.18 \%$ of total area; in 2007 , the area decreased by $29.74 \mathrm{~km}^{2}$, with an annual average shrinkage rate of $0.46 \%$. Afterwards, the area increased at an annual rate of $0.05 \%$ and reached up to $702.76 \mathrm{~km}^{2}$ by 2011 , accounting for $55.08 \%$ of total area.

Table 1. Area and proportion of different green space in Nanjing during 2000-2010.

\begin{tabular}{|c|c|c|c|c|c|c|}
\hline \multirow{2}{*}{ Type } & \multicolumn{2}{|c|}{2000} & \multicolumn{2}{c|}{2005} & \multicolumn{2}{c|}{2010} \\
\cline { 2 - 7 } & Area $\left(\mathrm{km}^{2}\right)$ & Proportion $(\%)$ & Area $\left(\mathrm{km}^{2}\right)$ & Proportion $(\%)$ & Area $\left(\mathrm{km}^{2}\right)$ & Proportion $(\%)$ \\
\hline Forest land & 490.24 & 11.17 & 475.94 & 10.85 & 496.18 & 11.31 \\
\hline Grassland & 53.52 & 1.22 & 57.67 & 1.31 & 57.71 & 1.32 \\
\hline Farmland & 2718.34 & 61.95 & 2499.29 & 56.96 & 2082.22 & 47.45 \\
\hline Water area & 409.27 & 9.33 & 372.66 & 8.49 & 450.26 & 10.26 \\
\hline Total & 3671.37 & 83.67 & 3405.56 & 77.61 & 3086.37 & 70.34 \\
\hline
\end{tabular}


Table 2. Area and proportion of different green space in Greater Manchester during 2000-2011.

\begin{tabular}{|c|c|c|c|c|c|c|}
\hline \multirow{2}{*}{ Type } & \multicolumn{2}{|c|}{2000} & \multicolumn{2}{c|}{2007} & \multicolumn{2}{c|}{2011} \\
\cline { 2 - 7 } & Area $\left(\mathrm{km}^{2}\right)$ & Proportion $(\%)$ & Area $\left(\mathrm{km}^{2}\right)$ & Proportion $(\%)$ & Area $\left(\mathrm{km}^{2}\right)$ & Proportion $(\%)$ \\
\hline Forest land & 139.69 & 10.95 & 82.77 & 6.49 & 68.93 & 5.40 \\
\hline Grassland & 463.99 & 36.36 & 384.31 & 30.12 & 417.48 & 32.72 \\
\hline Farmland & 82.37 & 6.46 & 174.48 & 13.67 & 161.77 & 12.68 \\
\hline Water area & 43.63 & 3.42 & 58.38 & 4.58 & 54.58 & 4.28 \\
\hline Total & 729.68 & 57.18 & 699.94 & 54.85 & 702.76 & 55.08 \\
\hline
\end{tabular}

From the perspective of inner composition, farmland and water area increased while forest land and grassland area decreased (Table 2). The development of multicenter city structure as well as the transformation and renovation of inner city have occupied some of forest land and grassland, but the implementation of greening policy drove the increase in farmland and water area, making the total area of green space remain relatively steady.

\section{Gradient Analysis}

\section{Changes in Distribution}

Because of different functions of inner city's regional layer serving as a carrier and different city construction intensity, green space of metropolitan area shows a distinct regional layer distribution characteristic, and changes in each layer distribution are significantly different.

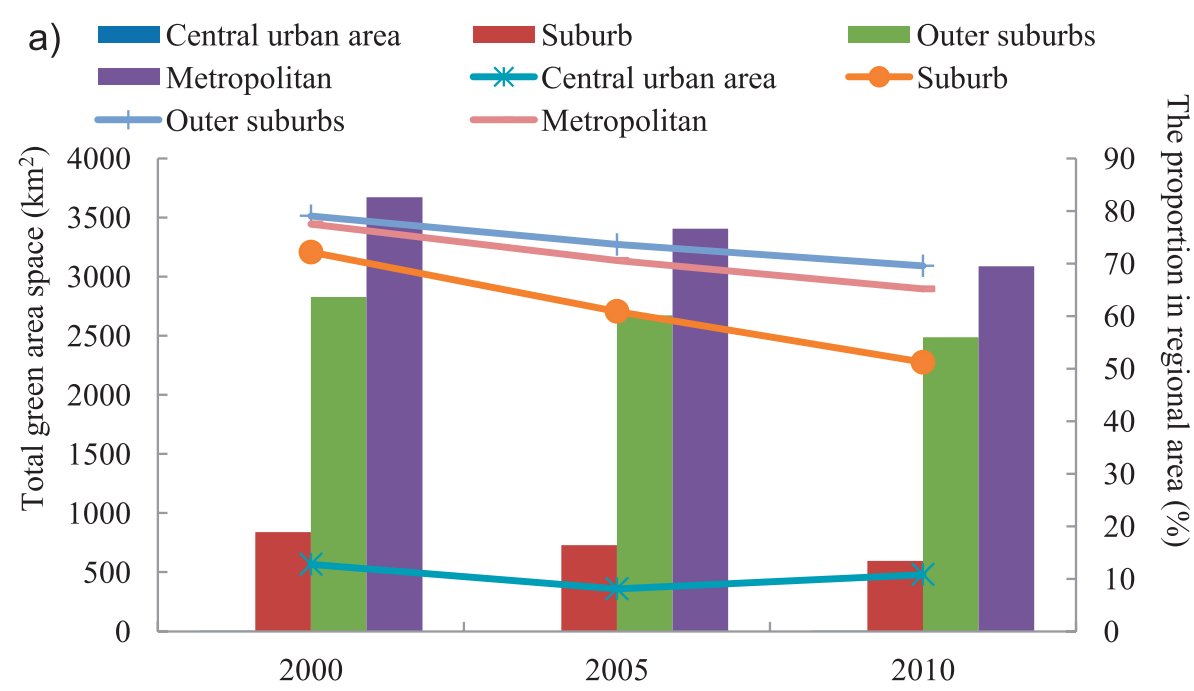

b)

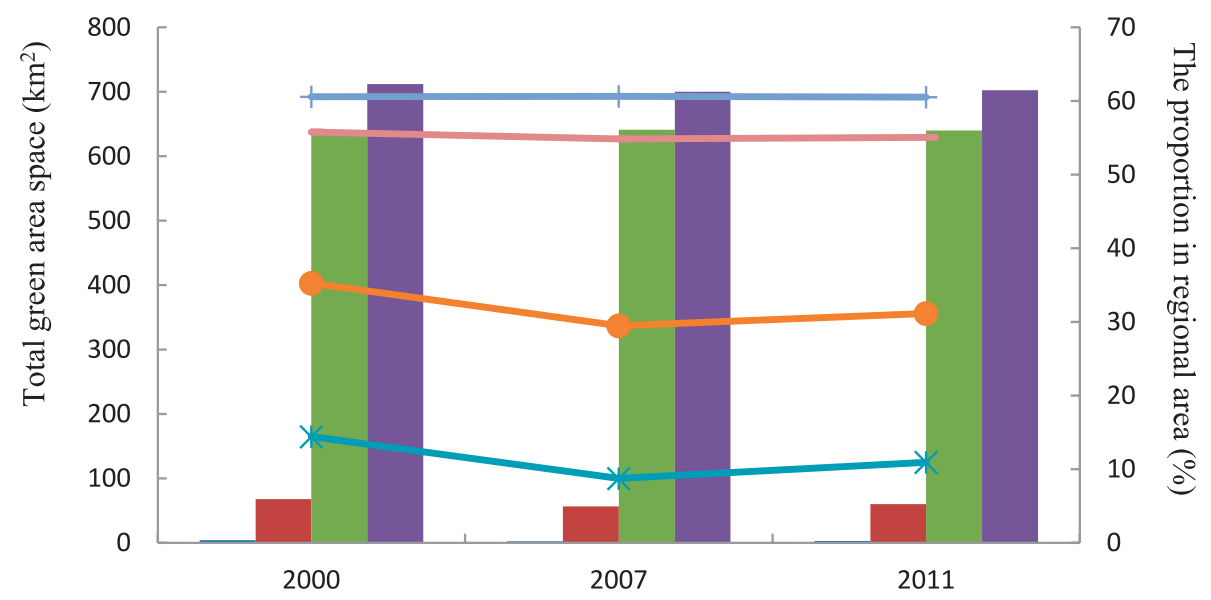

Fig. 3. Changes in green spatial scale a) Nanjing in 2000-2010, b) Greater Manchester in 2000-2011. 

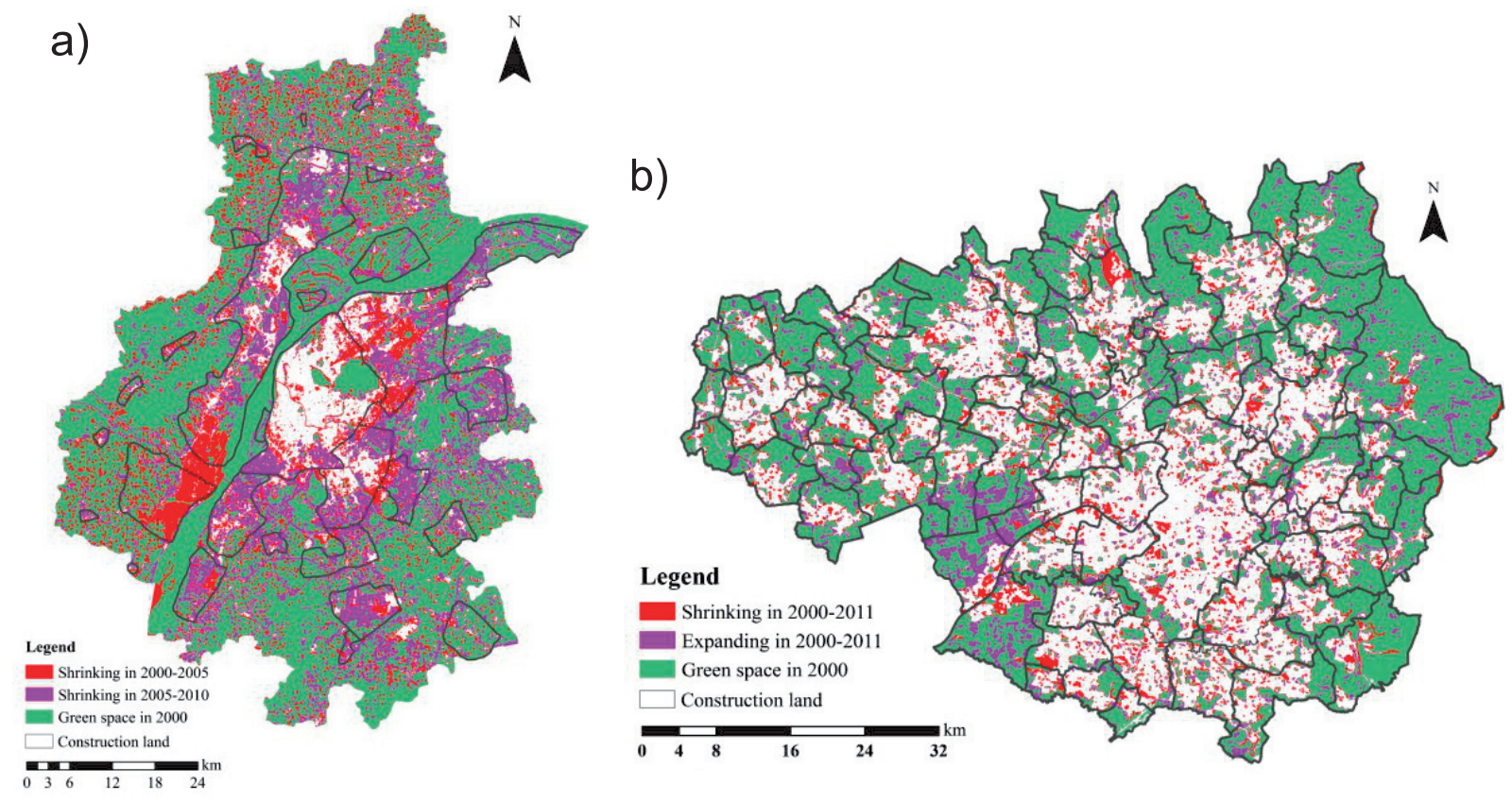

Fig. 4. Changes in green spatial scale of the metropolitan area a) Nanjing, b) Greater Manchester.

The green area in Nanjing metropolitan area significantly increased from central urban area to suburb and then to outer suburban area (Fig. 3a). During 2000-2010, green space area of each layer decreased but showed an obvious difference in variation trend. Green space in central urban area was basically steady, which decreased at first and then increased slightly. However, limited by urban space, the urban development inevitably expanded and spread outward, causing continuous decline of green space area in suburb and outer suburban district (Fig. 4a). What's more, green space area of each circle layer presents an inverted "U"-shaped curve, and mainly distributed within the scope of $25-45 \mathrm{~km}$, where large-scale green space patches are all distributed and green space area of each circle layer is greater than $500 \mathrm{~km}^{2}$ (Fig. 5a). The proportion of green space rapidly increases within $30 \mathrm{~km}$, and reaches up to about $82 \%$. During 2000-2005, the green space showed a progressive tendency of central city-sub-city-new town and the proportion of built-up area was all greater than $50 \%$. By 2010 , with the urban expansion, green space proportion of the built-up area declined, especially in two major sub-cities of Dongshan and Xianlin, Lukou on the outskirts and Banqiao New Town became key areas for land development, with the proportion exceeding 54\%, and construction land becomes main land-use type of the area, resulting in green space division and break.

Green space proportion of Greater Manchester multiplied from the center to outer suburbs (Fig. 3b). During 2000-2011, green space of each layer showed a general trend of shrinkage, but changing characteristics were different. In order to enhance urban public space quality and promote renovation of old city and ecological construction of industrial parks, green space in central urban area and suburb showed a trend of shrinkage at first and then expansion, which respectively increased to $2.92 \mathrm{~km}^{2}$ and $59.64 \mathrm{~km}^{2}$ by 2011 . However, concurrent with urban suburbanization development and green policies, green space kept balance between expansion and shrinkage in outer suburbs (Fig. 4b), and total area held relatively steady around $700 \mathrm{~km}^{2}$ in past ten years. Besides, total green space of Greater Manchester presents a $\Omega$-shaped distribution curve from the center to periphery, which is mainly distributed within the circle layer range of $15-18 \mathrm{~km}$ where green space area reaches up to $140 \mathrm{~km}^{2}$. Urban construction within $15 \mathrm{~km}$ of the central area stretches without break and green space scale increases layer by layer; for the area within 21-36 km, green space scale decreases progressively. From the perspective of relative scale, during 2000-2007, the green space proportion showed the change trend of 'decrease - increase - decrease increase', which spiked at $12 \mathrm{~km}$ and $24 \mathrm{~km}$ with the respective proportion of $65.70 \%$ and $67.58 \%$, indicating that green space construction at earlier stage focused on the suburbs. During 2007-2011, the green space proportion showed the trend of 'increase - decrease increase', and reached peak at $24 \mathrm{~km}$ and $36 \mathrm{~km}$ again (Fig. 5 b) with accounting for nearly $80 \%$.

\section{Changes in Intensity}

During 2000-2005, with the large-scale construction of industrial parks and Lukou Airport, the construction land of Nanjing metropolitan area expanded outward along the margin of central urban area, so that massive green space was occupied and the change intensity was 

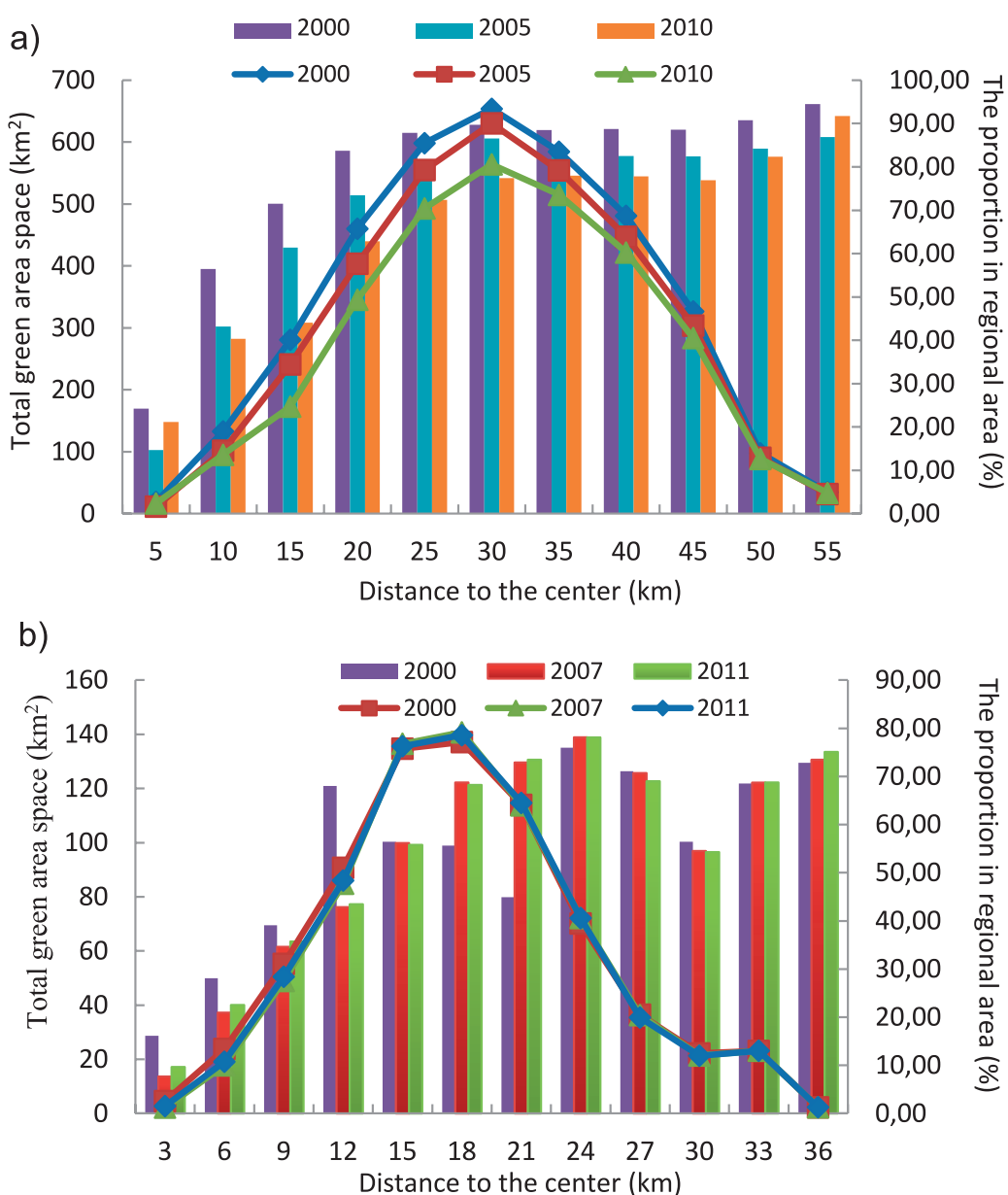

Fig. 5. Scale changes of green space a) Nanjing, b) Greater Manchester.

greater than 1.9 in the range of $5-20 \mathrm{~km}$ and reached the peak of 2.05 particularly at around $10 \mathrm{~km}$. However, at regions outside $20 \mathrm{~km}$, the intensity slowed down rapidly. Afterwards, with the acceleration of ecological improvement, green space change intensity gradually picked up. During 2005-2010, central urban area and its peripheral $5 \mathrm{~km}$ range started to build green parks, and ecological forest was built around $55 \mathrm{~km}$ of the outer suburbs, making the green space area on the rise and the change intensity was greater than 1. Green space showed a trend of shrinkage within the scope of $10-50 \mathrm{~km}$, and due to the development and construction of new city Xianlin, Jiangbei and Xincheng, shrinkage intensity within the scope of 10-35 km was greater than 1, which reached peak value around $15 \mathrm{~km}$ (Fig. 6a).

During 2000-2007, in Greater Manchester shrinkage intensity of green space within 3-12 km decreased progressively from inside to outside, reaching up to 1.2 at $3 \mathrm{~km}$. Reconstruction of the old city drove the development of central urban area and peripheral commerce and entertainment as well as promoted the construction of shopping mall, plaza, road and other facilities, as a result, the increase of space development intensity and demand for green space facilitated some of construction and unutilized land in outer suburbs to change into green land, causing green space to present an expanding trend at $15-27 \mathrm{~km}$, with the peak value of 0.25 and 0.31 at $18 \mathrm{~km}$ and $24 \mathrm{~km}$. During 2007-2011, green space at $3-12 \mathrm{~km}$ presented an expanding trend, but the intensity declined layer by layer; at $15-27 \mathrm{~km}$, the evolution intensity fluctuated greatly, and green space shrinkage coexisted with the expansion (Fig. 6b).

\section{Evolution Analysis}

\section{Direction Changes}

During 2000-2010, the most drastic green space decrease of Nanjing metropolitan area was in northeast direction, with the evolution intensity reached up to 6.02 , and followed by the direction of due east, southeast, due south and northwest, with the intensity was greater than 2, which were 3.97, 3.75, 2.54 and 2.11 respectively. During 2000-2005, except due south, evolution intensity of green space in all directions was even, which was about 1 , and green space in due south was relatively steady. During 2005-2010, directions with substantial decrease in green space were due north, due east, due south, northwest, northeast and southeast, meanwhile the evolution intensity in due west and southwest was weakened (Fig. 7a). 
a)

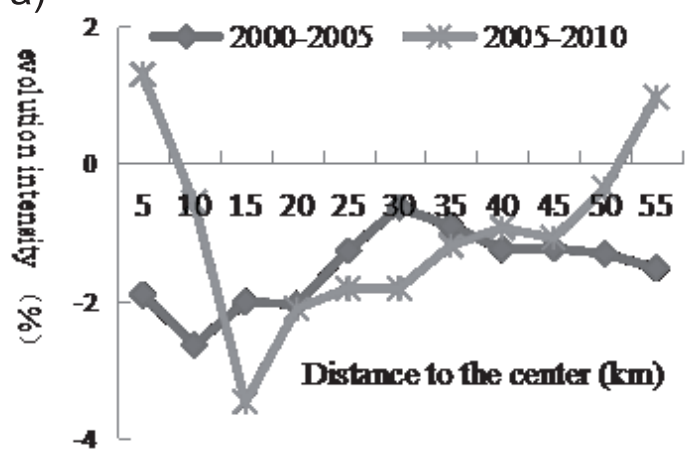

b)

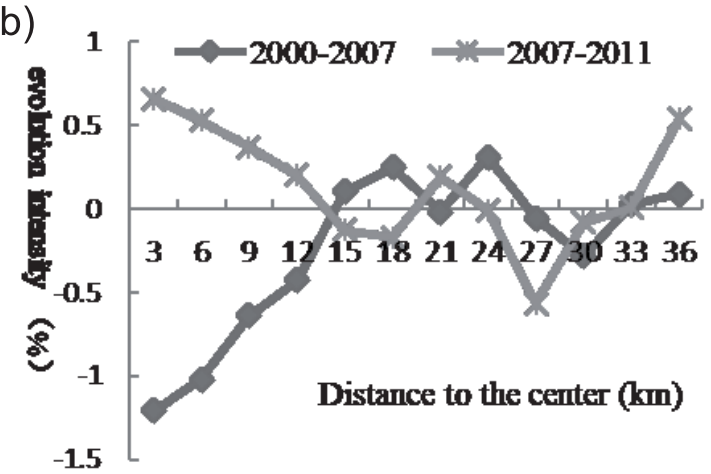

Fig. 6. Intensity changes of green space a) Nanjing, b) Greater Manchester.

During 2000-2011, green space of Greater Manchester shrank obviously in the south, and had the greatest evolution intensity of -1.46 , followed by the southeast and southwest. At the same time, green space in northeast direction presented an expanding trend, and had the lowest evolution intensity of 0.03 (Fig. 7b). As the main strip of urban space expansion, the south region had intense human activities, causing a great damage and erosion to the green space. During 2000-2007, the greatest green space shrinkage intensity was -1.04 in the south direction. During 2007-2011, green space in direct south showed the most obvious increase, with the intensity up to 1.54 . Green space in other directions shrank slightly, and the shrinkage intensity was the greatest in east direction.

a)

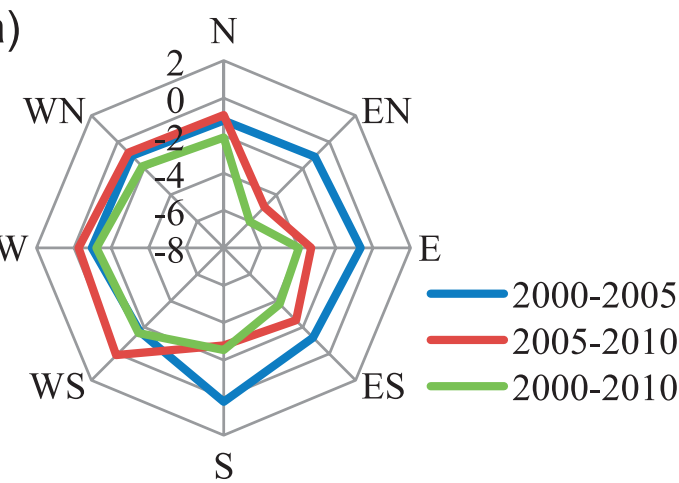

b)
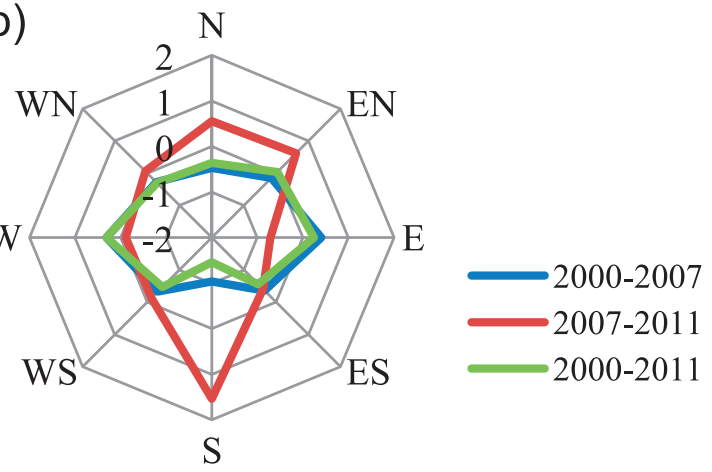

Fig. 7. Evolution intensity of green space in all directions a) Nanjing, b) Greater Manchester.

\section{Pattern Changes}

During 2000-2010, Nanjing's green space change hotspots moved to the central city, the northern suburbs and the western region, and the cold spots were transferred along the Jiangbei-Dongshan line of northsouth direction and the Yangtze River of northeastsouthwest direction and grouped in Xianlin, Dongshan and Jiangbei area, indicating that Nanjing's 'Green Nanjing' strategy achieved certain results in the main city and the remote suburbs during the period. Besides, suburban green space heavily occupied and a multicenter urban spatial structure formed gradually. During 2000-2005, hotspots was in a small account, mainly distributed in Longtan and Xiongzhou areas, and the secondary hotspots were concentrated in Tangshan and also distributed in Pukou, southwestern Jiangning and northern Yuhua District; cold spots were concentrated in Xianlin and Dongshan area, while the secondary cold spots are mainly distributed in Pukou and Liuhe (Fig. 8a). During 2005-2010, with the importance of green space increasing in the central urban area, hotspots and secondary hot spots began to appear in central districts of Gulou, Qinhuai, Xuanwu, etc., and expanded to Liuhe and Pukou, meanwhile the number and area of hot spots increased significantly; cold spots gradually separated from the central area due to the construction of new city and gathered in sub-cities of Banqiao, Xianlin and Dongshan, as well as new towns such as Tangshan, Lukou and Longtan. In addition, there are also distributions in Pukou and Xiongzhou (Fig. 8a).

During 2000-2011, the hotspots of the green space in Greater Manchester shifted to the central city, the suburbs and the northern outer suburbs while the cold spots dispersed to the western outer suburbs and eastern municipalities. The number and area of cold and hot spots all decreased, which indicates that the green space is relatively stable. Specifically, during 2000-2007, hotspots in the eastern outer suburbs and western margins were most prominent, especially in the southwestern Salford area, indicating that a large amount of construction land was converted into green 


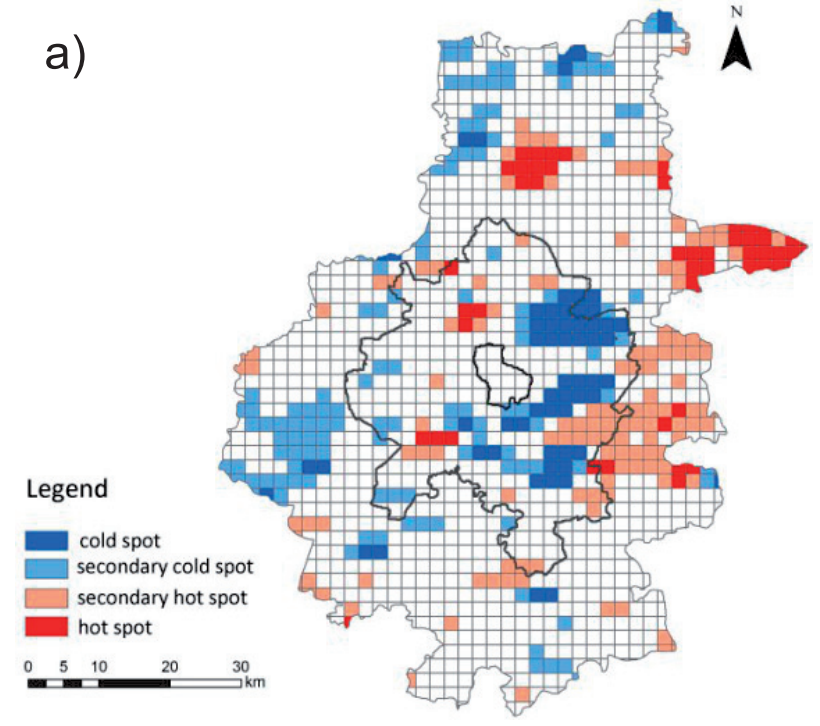

2000-2005

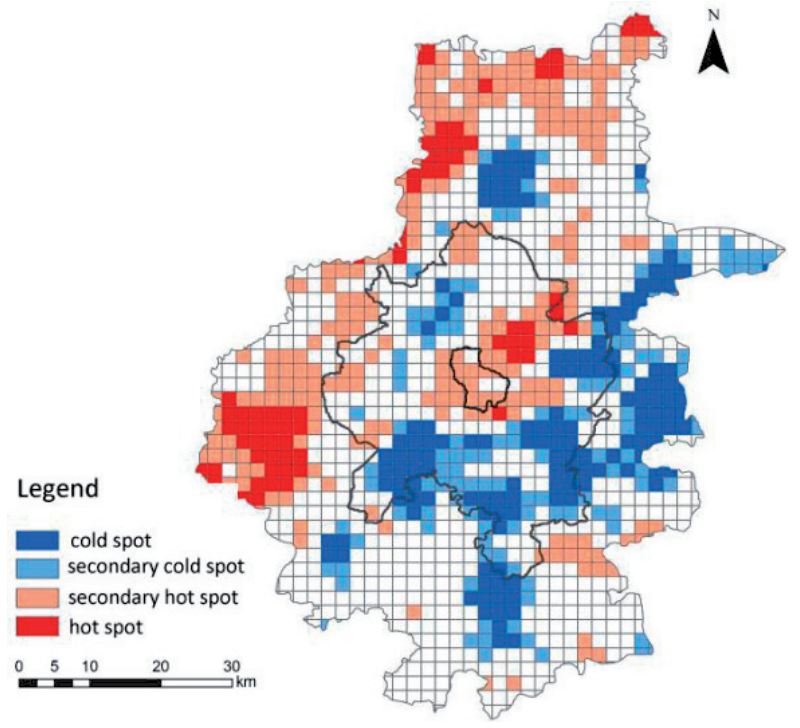

2005-2010

b)

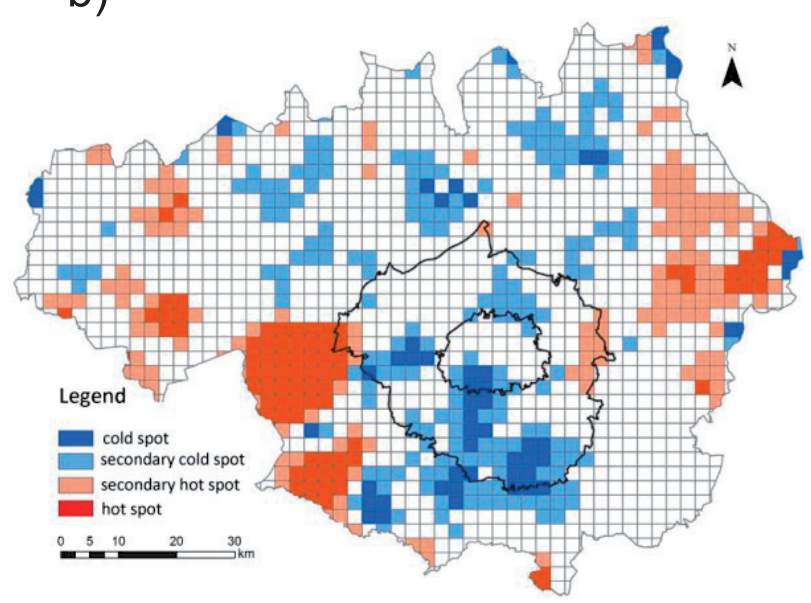

2000-2007

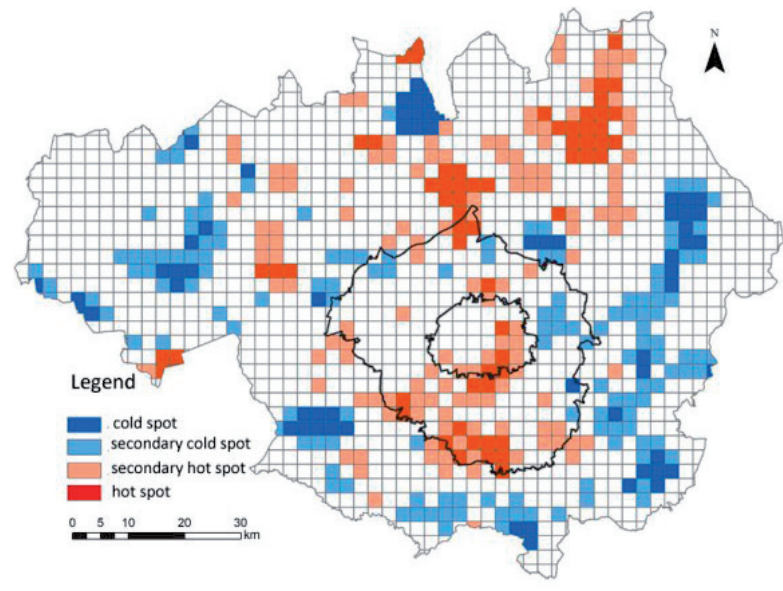

2007-2011

Fig. 8. Cold and hot spots of green space changes a) Nanjing, b) Greater Manchester.

space; cold spots were mainly distributed in central Manchester, southwest of Stockport and the junction of Salford and Tamside, as a result of the filling-type expansion of urban groups. During 2007-2011, cold and hot spots changed distinctly. Hotspots moved to the interior region, distributed in Manchester, northern Berry and Rochdale, while cold spots shifted outwards and evenly distributed in Wigan, Tamside, Rochdale and other districts.

\section{Model Changes}

Green space evolution in Nanjing metropolitan area focuses on outspread shrinkage. It transfers from main urban area to the sub-cities and new cities owing to the urban expansion and has a significant trend of relocation, which is relatively scattered in space (Fig. 9a). During 2000-2005, the evolution model was mainly dominated by endocytosed and outspread shrinkage. Endocytosed shrinkage mainly concentrated in urban area fringe, sub-city of Xianlin and Dongshan, and also scattered in old town of Jiangbei. Outspread shrinkage mainly focused in the south fringe of central urban area, sub-city of Xianlin and Dongshan, new city of Binjiang and Lukou; green space in new city of Longpao and Jiangbei chemical industrial park showed perforated shrinkage and the connectivity was destroyed. In addition, with the implementation of the 'green Nanjing' strategy, the green space of Qiaolin, Dongshan, Jiangbei and outer suburbs expanded along the main highway. During 2005-2010, the endocytosed shrinkage of green space mainly distributed in subcities of Dongshan, Jiangbei and new town of Banqiao; outspread shrinkage had obvious relocation trend, focusing in the sub-city of Xianlin, Dongshan, new city of Tangshan, Chunhua, Binjiang and Lukou and 
a)

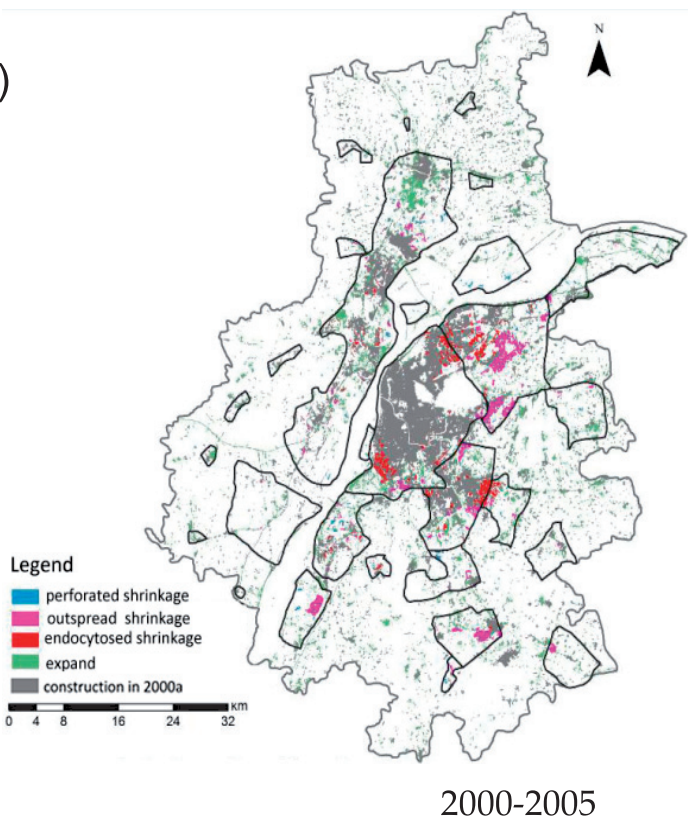

b)

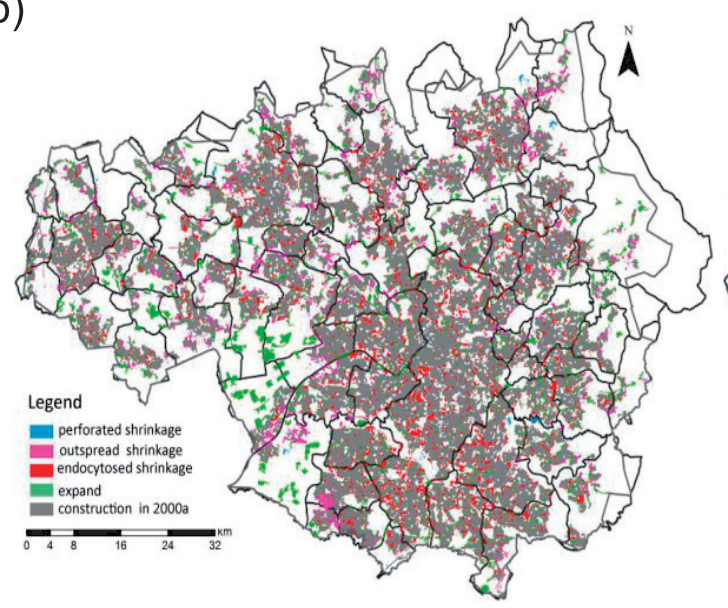

2000-2007

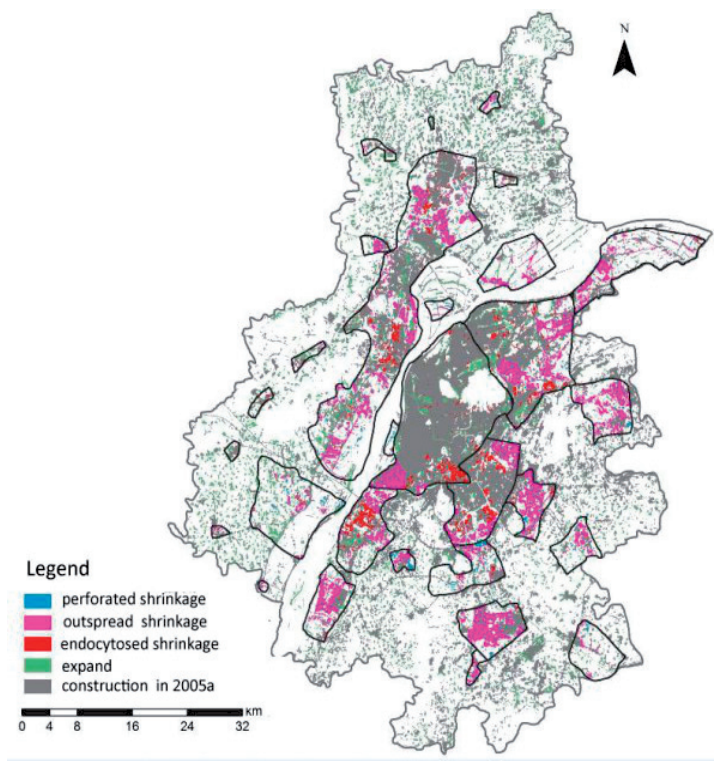

2005-2010

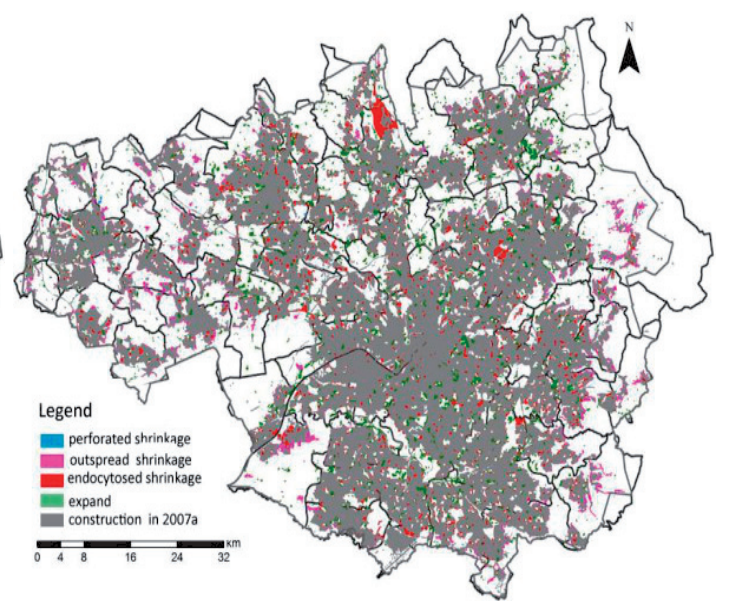

2007-2011

Fig. 9. Evolution model of green space a) Nanjing, b) Greater Manchester.

Xiongzhou; and the perforated shrinkage concentrated in new towns continued to expand outward, breaking the connectivity of the peripheral green space. Meanwhile, a small amount of expansion also appeared in fringe of of Xianlin, Qinhuai River and Xuanwu Lake coast and Jiangbei district.

In Greater Manchester metropolitan area, green space expansion coexists with the shrinkage, which focuses on endocytosed shrinkage. From the perspective of spatial distribution, it presents the evolution of endocytosed shrinkage to outspread shrinkage from inside to outside. Middle area of the built-up land focuses on endocytosed shrinkage and green area increase from the center to periphery (Fig. 9b). During 2000-2007, endocytosed shrinkage was mainly distributed in Manchester and the border region of Salford and Trafford, and was also extensively distributed in the center of all towns and city clusters; fringes of construction land were the major area of outspread shrinkage, which was mainly distributed outside the construction space of Wigan, Bolton, Buly, Rochdale and Oldha, and was also concentrated in the connection area of urban and rural area in the southwest. Perforated shrinkage was scattered in outer suburban area and the green space expanded towards the southwest. During 2007-2011, the evolution of green space focused on expansion, which was distributed in the central urban area, fringe of the south suburb and the north of outer suburbs such as Rochdale, Bury, Bolton and other towns, where part of inner construction land evolved into grassland and water area; endocytosed shrinkage of the green space was scattered in central urban area, suburb and outer suburb with Bolton, Bury, Rochdale and Oldham clusters, where the intensive land use had a higher level; moreover, outspread shrinkage of the green land mainly focused in the east and southwest of the built-up area. 


\section{Discussion}

Quantitatively analyzing the distribution and evolutionary characteristics of green space enable us to better understand the impact of urban development on the spatiotemporal changes of green space. Rapid urbanization has profoundly changed urban green space [40], and affected its distribution. Scales of green space in Nanjing and Greater Manchester both showed a trend of increase from central area to suburban area, which is just opposite of the distribution of construction space, and largely due to the encroachment of built-up area. In Nanjing, the scattered greening strategy in central city has achieved results in recent years [41], but reduction is still dominant, resulting in the green space continues to decrease. This is consistent with Rafiee et al. [18] finding that under the influence of rapid urbanization, green space areas in Mashad city became isolated and decreased, with large-area reduction and scattered increase coexisting. Besides, the discovery of green space cold spots transferring to urban suburbs also coincided with Tang et al. [42] study in large cities such as Beijing, Tianjin, and Shijiazhuang. UK is the country that started exploring urban green construction earlier in the world [43], and in Greater Manchester, green space construction has been relatively mature. As a consequence, green space area has changed but not severely, and its increase mainly comes from the inner city renewal and transformation. The results are within our expectations and certainly reliable.

The spatiotemporal evolution of green space is affected by various factors such as socioeconomic growth, industrial development, value orientation, and urban management concept [44-46]. And the influencing factors of cities in different development stages often varied a lot, resulting in the differences in the layout and changes of urban green space. Generally speaking, when a city is in the high-speed developing stage, a large amount of construction space is required to carry the social production and life [47], at the same time, the government and residents would pay more attention to the economic interests of the land, resulting in the continuous expansion of construction land, especially along the external traffic axis and rivers, as well as the large eroding of urban green space. As the central city becoming saturated, restrictions on land resources being more prominent and industrial structure needing adjusting, construction land is urged to expand so that new cities and development zones arise then [38, 48], leading to green space in the suburbs gradually being encroached. With the economic continuously improving and the city entering into a stable stage, industrial upgrading and adjustment requires for better ecological environment, which prompting people to strengthen the protection of green space; and the government's positive guiding effect on green space also gradually increases [49]; in addition, in view of the fact that green space offers citizens aesthetic enjoyments, recreational opportunities and physical and psychological well- being [50], residents' desire for green area is becoming stronger. As a result, green space of cities in this stage usually increases. Nanjing, one of the most vigorous cities in China, is still in a stage of rapid urbanization, with the population constantly growing, construction lands expanding and transferring to suburbs continually, citizens beginning to emphasize the value of green space and the government starting to manage green space by some policies and regulations. As for Greater Manchester, it has entered a relatively stable development stage, where the industrial structure has upgraded, the inner city has renewed and transformed, residents' demand for good ecological environment is high and the management system of green space is relatively refined. Consequently, affected by the different conditions above, the two cities differed apparently on changing characters of green space. This may provide guidance for the authority of Nanjing to better administrate the land in the process of further development.

This study carried out an evaluation of the changes in green space of Nanjing and Greater Manchester over the past decade by using remote sensing data. It not only expounded the scale changes of urban green space under different development models, but also illustrated the heterogeneity in the distribution of green space and its evolution in depth to better understand the interaction between construction space and green space, making up for the lack of spatiotemporal evolution analysis in the previous researches. However, due to the inevitable error in the process of manually images interpreting, the accuracy of the results may be biased, but it won't affect much on the description of green space change trend; in addition, the selection of time nodes in two cities does not correspond completely due to the limitation of data availability. The pressure on the green space and how to protect the ecology, greenness and health of the residents' living environment will be the key concerns. And the analysis of the transformation of specific landscape types within the green space should be further discussed in future studies.

\section{Conclusions}

Based on multi-temporal Landsat images, this study quantitatively analyze the dynamic of green space in Nanjing and Greater Manchester. We found that the green space in Nanjing has increasingly decreased in the period of 2000-2010, which was mainly due to the so large-scale reduction of cultivated land that the increase of forest land and water area brought by urban greening was still insufficient to cover the gap. During the period of 2000-2011, green space area in Greater Manchester decreased first and then increased; and after entering a stage of relatively stable, although the urban construction and greening policies inevitably led to changes in green space, the extent is not large and the overall scale didn't change much. 
In terms of gradient characteristics, green space area in the two cities both has an obvious distribution characteristic of increasing from the central city to the suburbs and the outer suburbs, but changed differently. In Nanjing, green space in the central area has decreased first and then increased while in suburbs and outer suburbs have continued to decrease. As for Greater Manchester, the amounts of green space decreased first and then increased in central and suburban areas, where the intensity value also changed relatively significantly, but in out suburbs, green space remained basically invariant.

We also found that the greenspace's spatiotemporal evolutions, especially the evolution model, are obviously different in Nanjing and Greater Manchester. In terms of evolution model, in Nanjing, outspread shrinkage was the main evolution model and tended to transfer to the new towns in suburban area, followed by endocytosed contraction occurring inside construction areas. Compared with Nanjing, the green space of Greater Manchester evolved with smaller scale and more scattered distribution. And the evolution model was dominated by endocytosis-type, transferring to the suburbs; outspread shrinkage is mainly scattered on the edge of construction land.

Comparing the changes in green space between Nanjing and Greater Manchester, urbanization in Nanjing has continued to expand outwards, gradually forming a multi-center urban structure. Greater Manchester has achieved redevelopment through urban renewal, and focused on inner urban greening, with green space filling in central areas and building urban green belts based on multi-center urban spatial structure to limit the expansion of urban construction.

When it comes to urban transformation and development, Nanjing is supposed to fully learn lessons from Greater Manchester. The redevelopment and functional replacement of land within construction space would control the growth of construction land, as well as improve the urban compactness. In addition, green space construction and optimizing the allocation should be seriously taken to regulate the relationship between construction and green space, and enhance the capacity of ecological services.

\section{Acknowledgments}

This research was funded by National Key R\&D Program of China (No. 2018YFD1100101) and the National Natural Science Foundation of China (No. 71573250).

\section{Conflict of Interest}

The authors declare no conflict of interest.

\section{References}

1. TUMER T. Open space planning in London: From standards per 1000 to green strategy. Town Planning Review, 63, 365, 1992.

2. TU X., HUANG G., WU J. Review of the relationship between urban greenspace accessibility and human wellbeing. Acta Ecologica Sinica, 39, 421, 2019.

3. PAULEIT S., GOLDING Y. The spatial impact of urban compaction. The Town Planning Review, 76, 143, 2005.

4. NUTSFORD D., PEARSON A.L., KINGHAM S. An ecological study investigating the association between access to urban green space and mental health. Public Health, 127, 1005, 2013.

5. LIU X. A Research on Evaluation Index of Urban Green Space System Planning. Dissertation, Nanjing Forestry University, China, 2015.

6. YANG Z., ZHANG H., DING Y., SUN Y. Progress and prospect on urban green space research. Progress in Geography, 34, 18, 2015.

7. LI Y. Research the Biodiversity of City Green Space System Planning - Taking Sanhe City Green Space System Planning as an Example. Urbanism and Architecture, 06, 43, 2014.

8. LIU F., YAN W., KONG F., YIN H., BAN Y., XU W. A review on the urban green space cooling effect based on field measurement of air temperature, 28, 1387, 2017.

9. BARBOSA O., TRATALOS J.A., ARMSWORTH P.R., DAVIES R.G., FULLER R.A., JOHNSON P., GASTON J.K.J. Who benefits from access to green space? A case study from Sheffield, UK. Landscape and Urban Planning, 83, 187, 2007.

10. JORGENSEN A., HITCHMOUGH J., CALVERT T. Woodland spaces and edges: their impact on perception of safety and preference. Landscape and Urban Planning, 60, 135, 2002.

11. BRICKER K.S., HENDRICKS W.W., GREENWOOD J.B., ASCHENBRENNER C.A. Californians' perceptions of the influence of parks and recreation on quality of life. Journal of Park and Recreation Administration, 34, 64, 2016.

12. EKKEL E.D., DE VRIES S. Nearby green space and human health:Evaluating accessibility metrics. Landscape and Urban Planning, 157, 214, 2017.

13. WANG Y., WANG S., QIN J. Spatial evaluation of land urbanization level and process in Chinese cities. Geographical Research, 33, 2228, 2014.

14. CASPERSEN O.H., KONIJNENDIJK C.C., OLAFSSON A.S. Green space planning and land use: An assessment of urban regional and green structure planning in Greater Copenhagen. Geografisk Tidsskrift-Danish Journal of Geography, 106, 7, 2006.

15. HOSSEINI S.J.F., LAING R. The role of plant clinics in sustainability of urban green spaces in Tehran. International Journal of Sustainable Development \& World Ecology, 18, 128, 2011.

16. YE L., XING Z., YAN W. Smart Planning of UrbanFringe Greenspaces: Core Issues, Conceptual Framework and Planning Strategies. Urban Planning Forum, 01, 30, 2017.

17. QIAN Y., ZHOU W., LI W., HAN L. Understanding the dynamic of greenspace in the urbanized area of Beijing based on high resolution satellite images. Urban Forestry \& Urban Greening, 14, 39, 2015. 
18. RAFIEE R., MAHINY A.S., KHORASANI N. Assessment of changes in urban green spaces of Mashad city using satellite data. International Journal of Applied Earth Observation and Geoinformation, 11, 431, 2009.

19. TIAN Z., WANG R., ZHAO Q., MA X. Study on temporal and spatial variations in the ecosystem service value of Beijing greenlands from 2000 to 2012. Journal of China Agricultural University, 22, 76, 2017.

20. SIKUZANI Y., KOUAGOU R.S., MARÉCHAL J., ILUNGA E.I.W., MALAISSE F., BOGAERT J., KANKUMBI F.M. Changes in the Spatial Pattern and Ecological Functionalities of Green Spaces in Lubumbashi (the Democratic Republic of Congo) in Relation with the Degree of Urbanization. Tropical Conservation Science, 11, 1, 2018.

21. CHEN Y., CAI X., TONG C. Research on the temperature effect of the urban green space evolution process based on remote sensing: Taking the main urban area of Fuzhou as an example. Acta Ecologica Sinica, 7, 2439, 2020.

22. LI Q., LI X., LU L., CHENG Y., WU R. Remote sensing analysis of spatiotemporal changes in Beijing's green space. Software, 40, 37, 2019.

23. DI X., HOU X., WU L. Land Use Classification System for China's Coastal Zone Based on Remote Sensing. Resources Science, 36, 463, 2014.

24. LI F., XIE S., LI X. The Spatio-temporal Evolution of Green Spaces in Central Beijing Based on Multi source Data (1992-2016). Landscape Architecture, 25, 46, 2018.

25. CHEN K., GONG J., LIU Y., CHEN X. The Spatialtemporal Differentiation of Green Space and Its Fragmentation during the Past Thirty-five Years in Guangzhou. Journal of natural resources, 31, 1100, 2016.

26. HAN H., YANG C., SONG J. The Spatial-Temporal Characteristic of Land Use Change in Beijing and Its Driving Mechanism. Economic Geography, 35, 148154/197, 2015.

27. JIA Q. Remote Sensing Research of Green Space Evolution and Its Cool Island Intensity. Dissertation, Tianjin University, China, 2015.

28. TIAN Y., JIM C.Y., TAO Y., SHI T. Landscape ecological assessment of green space fragmentation in Hong Kong. Urban Forestry \& Urban Greening, 10, 79, 2011.

29. JIN J., WANG C., JIA B. Spatio-Temporal Patterns of Evolution Urban Greenspace during the Last Three Decades in Four Typical Cities of China. Scientia Silvae Sinicae, 56, 61-72, 2020.

30. BYOMKESH T., NAKAGOSHI N., DEWAN A.M. Urbanization and green space dynamics in Greater Dhaka, Bangladesh. Landscape and Ecological Engineering, 8, 45, 2012.

31. LI Y. The Change of Urban Green Space and its impact on Eco-environmental effects: A case study in Shanghai. Dissertation, Fudan University, China, 2012.

32. JAEGER J.A.G. Landscape division, splitting index, and effective mesh size: new measures of landscape fragmentation. Landscape Ecology, 15, 115, 2000.

33. ZHAO H., WANG S., MENG F., NIU M., LUO X. Green space pattern changes and its driving mechanism: a case study of Nanjing metropolitan area. Acta Ecologica sinica, 40, 7861, 2020

34. LI J. Study on Spatial Performance Evaluation of Urban Green Park Recreational Service Capability and Layout
Optimization: A Case Study of the Central District of Xi'an City. Dissertation, Northwest University, China, 2019.

35. LI N., XIAO Y., XIE G., ZHANG B., WANG S., ZHANG Y., LIU C., SUN Y. Temporal and spatial change of urban green space pattern in Beijing. Resources Science, 37, 1141, 2015.

36. LIU X., LI X., CHEN Y., QIN Y., LI S., CHEN M. Landscape Expansion Index and Its Applications to Quantitative Analysis of Urban Expansion. Acta Geographica Sinica, 64, 1430, 2009.

37. LIU J., WANG X., ZHUANG D., ZHANG W., HU W. Application of Convex Hull in Identifying the Types of Urban Land Expansions. Acta Geographica Sinica, 58, $885,2003$.

38. ZHAO T. Urban Land use expansion and its driving Mechanism in China. Dissertation, Institute of Geographic Sciences and Natural Resources Research, China, 2005.

39. GAO J. Study on the Model and Mechanism of Urban Construction Land expansion: a case study of Nanjing Urban area. Dissertation, University of Chinese Academy of Sciences, China, 2013.

40. LI Y., HUANG C., ZHANG Y. Investigating Spatiotemporal Patterns of Landscape Gradient and Diversity of Urban Green Spaces of Shanghai in Response to Rapid Urbanization. Ecology and Environmental Sciences, 25, 1115, 2016.

41. GUO F. The Research on the Urban Green Space Form Based on Urban Morphology. Dissertation, Nanjing Tech University, China, 2013.

42. TANG H., LIU W., YUN W. Spatiotemporal Dynamics of Green Spaces in the Beijing-Tianjin-Hebei Region in the Past 20 Years. Sustainability, 10, 29, 2018.

43. JIANG Y., SHI T., ZHAO S. Development of control administration concerning regional green space in the UK and its implications. City Planning Review, 39, 79, 2015.

44. HE Z. Driving mechanism of the development of urban green space in China based on panel data. Dissertation, Fujian Normal University, China, 2017.

45. SHAO D., WU D. Landscape Pattern Evolvement of Green Space: A Case Study of the Central Area of Nanjing. Chinese Landscape Architecture, 32, 103, 2016.

46. CHENG C., HU Y., ZHAO M. Progress and prospect of the spatiotemporal change and ecosystem services evaluation of urban green space pattern. Progress in Geography, 39, 1770, 2020.

47. TURRINI T., KNOP E. A landscape ecology approach identifies important drivers of urban biodiversity. Global Change Biology, 21, 1652, 2015.

48. ZONG R. Research on Spatial layout pattern of Green Space System in Administractive Region of Xi'an Based on Carbon Sink Performance. Dissertation, Xi'an University of Architecture and Technology, China, 2018.

49. NOR A.N.M., CORSTANJEA R., HARRISA J.A., BREWER T. Impact of rapid urban expansion on green space structure. Ecological Indicators, 81, 274, 2017.

50. ORD K., MITCHELL R., PEARCE J. Is level of neighbourhood green space associated with physical activity in green space? The international journal of behavioral nutrition and physical activity, 10, 127, 2013. 